\title{
The Impact of Social Media Usage on Depression Cognition and Help-seeking Behavior: A Study Based on Grounded Theory
}

\author{
Yijing Guo ${ }^{1}$ and Yunjuan Cai ${ }^{1, *}$
}

\author{
${ }^{1}$ School of Public Affairs and Administration, University of Electronic Science and Technology of China, \\ Chengdu, Sichuan 611731, China \\ *Corresponding author. Email: junecyj@163.com
}

\begin{abstract}
Depression is a serious psychological disorder, but at present, the public and patients have insufficient understanding of it. In order to make better use of social media to spread depression information, promote public depression cognition and stimulate help seeking behavior, it is necessary to study the impact path of social media use on public depression cognition and help-seeking behavior. By selecting the sample data from in-depth interviews, using the grounded theory research method and three-level coding, this paper summarized the relevant concept categories, and constructed the impact model of social media use on public depression cognition and help-seeking behavior. The study found that social media contact and social media trust shape public perceived knowledge, risk perception and stereotype. Perceived knowledge, risk perception and stereotype directly affect public willingness and help-seeking behavior.
\end{abstract}

Keywords: social media, health communication, depression, help-seeking behavior

\section{INTRODUCTION}

As a mental disease, depression has become a serious global health problem. According to the data report on the World Health Organization website, an estimated 350 million people worldwide suffer from depression, and the number of suicides due to depression is estimated to be as high as 1 million every year. For a long time, depression cannot enter the public view as a disease in China. The public has low awareness of depression and lack of basic prevention and treatment awareness. Medically, patients with depression may save lives by seeking help in time, but they are often unwilling to take action because of lack of awareness, shame and other reasons [1]. The screening and treatment of depression should not only rely on the efforts of social medical institutions. It is particularly important to correct the public's cognitive bias and stimulate patients' willingness and behavior to help.

With the development of social media, more and more people choose to obtain and exchange health information from social media. Social media plays an important role in the healthy communication of depression information. More and more scholars have carried out relevant research. The research mainly focuses on the impact of social media use on the degree of depression, the disclosure of depression information in social media, the stigmatization of depression in social media, and the social impact of celebrity depression exposure in social media.

$H$. Erin Lee et al. investigated the impact of social media use on the mental health of specific groups of disabled people in Korea and found that the higher the intensity of SNS use and online community use, the higher the level of tool support and information support, resulting in the lower level of depression [5]. Zhang Zheng found that negative information in WeChat circle of friends will have an impact on users' depression. However, not all negative information will increase depression, but will have different effects on people with different personalities [6]. Berry's research on twitter found that Twitter has become an important platform for individuals to explore mental health problems. Twitter mainly focuses on four topics: community awareness, awareness raising and stigma elimination, safe expression space, response and authorization. Twitter brings perceptible therapeutic benefits to individuals by providing support, information and self-management strategy suggestions, At the same time, it can be used to fight stigma and improve the understanding of mental health problems, which in turn promotes the social interests of depression groups [7]. Moreno found that posts about stress and depression are common on Facebook, and people who get online help from friends are more likely to openly discuss their depressive symptoms on Facebook [8].

Related studies have discussed the impact of media on audience cognition or health behavior, but they lack the test in the research problems related to depression, and lack the analysis of the overall mechanism of impact. Using the grounded theory research method, this paper puts forward the theoretical framework of the impact of social media use on public depression cognition and help-seeking behavior, and analyses the relationship and action mechanism between social media and public depression cognition and 
help-seeking behavior, which is helpful to better study how to use social media to carry out the healthy dissemination of depression information, so as to promote the positive help-seeking behavior related to depression, In order to improve the cure rate of depression.

\section{RESEARCH DESIGN}

\subsection{Research Methods}

In this paper, in-depth interviews are used to collect text data. The interview method is unstructured interview, which mainly uses natural communication and open dialogue to obtain the interview text of public social media use, depression cognition and help-seeking behavior. Then, based on grounded theory, this paper analyses the impact of social media use on depression cognition and helpseeking behavior.

Grounded theory emphasizes the mining of original data, which is a method to establish theory from bottom to top. This method can find research problems from life without theoretical assumptions. After data collection, open coding, spindle coding and selective coding are carried out on the data, and concepts and categories are summarized and refined from the original data. It focuses on continuous comparison and induction until the theory reaches saturation and finally forms a theoretical framework [9].

\subsection{Sample Selection}

A total of 21 samples were selected by purposeful sampling. Through WeChat voice interview and face-toface interview, in-depth interviews were carried out in an undisturbed environment. The interview duration of each respondent is 20-40 minutes. Among these respondents, 16 self-reported good psychological status, 3 with mild depression, 2 with moderate depression and no major depression. In terms of age, the age range of respondents is 15-50 years old, mainly 20-30 years old. In terms of occupation, the respondents include college students, college teachers, programmers, civil servants, engineers, etc. In terms of educational background, the respondents' educational background is mainly bachelor's degree and master's degree, considering a small number of junior colleges, senior high school and junior high school groups. Through preliminary interviews, most respondents used social media such as WeChat, QQ, micro-blog, ZhiHu, and so on. The frequency of using social media was higher and the platform was more extensive.

\section{IMPACT MODEL CONSTRUCTION}

\subsection{Open Coding}

Open coding is the first step in grounded theory analysis. It is a process of extracting initial concepts from the original data and completing the summary and classification of similar topics, which requires coding the original data sentence by sentence [7].

Table 1 Open Coding Table

\begin{tabular}{|l|l|}
\hline \multicolumn{1}{|c|}{ Concept Tag } & \multicolumn{1}{|c|}{ Initial Category } \\
\hline $\begin{array}{l}\text { A1 browsing, A2 thumb up, A3 share, A4 search information, A5 participate in the discussion, } \\
\text { A6 interactive communication, A7 recommendations }\end{array}$ & $\begin{array}{l}\text { B1 Social media } \\
\text { contacts }\end{array}$ \\
\hline $\begin{array}{l}\text { A8 word of mouth, A9 accustomed to accept, A10 authority, A11 professional, A12 reliability, } \\
\text { A13 objectivity, A14 authenticity }\end{array}$ & $\begin{array}{l}\text { B2 Social media } \\
\text { trust }\end{array}$ \\
\hline $\begin{array}{l}\text { A15 better understand, A16 deepen impression, A17 improve knowledge level, A18 can explain } \\
\text { to others, A19 basic knowledge, A20 prevention knowledge, A21 treatment knowledge, A22 } \\
\text { knowledge of the causes of the disease }\end{array}$ & $\begin{array}{l}\text { B3 Perceptual } \\
\text { knowledge }\end{array}$ \\
\hline $\begin{array}{l}\text { A23 disease popularization, A24 risk of disease, A25 disease probability, A26 affects mood, A27 } \\
\text { affects life, A28 affects social interaction, A29 increase cost, A30 harm health, A31 cause serious } \\
\text { consequences }\end{array}$ & B4 Risk perception \\
\hline $\begin{array}{l}\text { A32 psychosis, A33 madness, A34 danger, A35 harm another person, A36 is prone to suicide, } \\
\text { A37 unable to take care of itself, A38 confused thinking, A39 lack of communication, A40 is } \\
\text { bad-tempered, A41 fragile heart, A42 melodramatic }\end{array}$ & B5 Stereotypes \\
\hline $\begin{array}{l}\text { A43 willing to ask family members for help, A44 willing to turn to friends for help, A45 willing } \\
\text { to ask the teacher for help, A46 willing to call psychological intervention hotline, A47 willing to } \\
\text { do psychological counseling, A48 is willing to go to the hospital }\end{array}$ & $\begin{array}{l}\text { B6 Behavioral } \\
\text { intention to ask for } \\
\text { help }\end{array}$ \\
\hline $\begin{array}{l}\text { A49 help a family member, A50 ask a friend for help, A51 ask the teacher for help, A52 } \\
\text { psychological intervention hotline for help, A53 seek psychological counseling, A54 get help } \\
\text { from a doctor }\end{array}$ & $\begin{array}{l}\text { B7 Actual help- } \\
\text { seeking behavior }\end{array}$ \\
\hline
\end{tabular}


In order to ensure the accuracy of interview texts and the reliability and validity of coding, initial concepts are mined based on the original statements of interviewees. In the process of coding, the original texts of the interviewees were screened out, and those irrelevant to this study were eliminated. Then, 18 original interview texts were encoded by multiple people respectively, and the other 3 were used for the final model saturation test. The coding process requires the elimination of personal thinking stereotypes and prejudices, the analysis of all scattered interview data, the gradual "label" of each statement, the continuous extraction of initial concepts, and then induction and classification based on similar, related, causal and other relations. In the end, a total of more than 300 original statements were obtained, forming 54 concept labels, and 7 initial categories including social media contact, social media trust, perceived knowledge, risk perception, stereotype, behavioral intention to seek help, and actual help-seeking behavior were further summarized, as shown in Table 1. In order to ensure the representativeness of the interview samples, the selected concept labels should appear at least three times in the overall interview samples.

\subsection{Axial Coding}

Axial coding takes "condition- context- action / interactionresult" as the basic guiding ideology, clusters and summarizes the extracted categories, further analyses the logical connotation between various categories, and generates clear main categories [8].

Through the analysis of interview records, this study analyses the causal and logical relationships at the conceptual level of the above seven initial categories, classifies them, and finally forms three main categories, which are represented by social media use (C1), depression cognition (C2) and help-seeking behavior (C3), as shown in Table 2 .

Table 2 Axial Coding Table

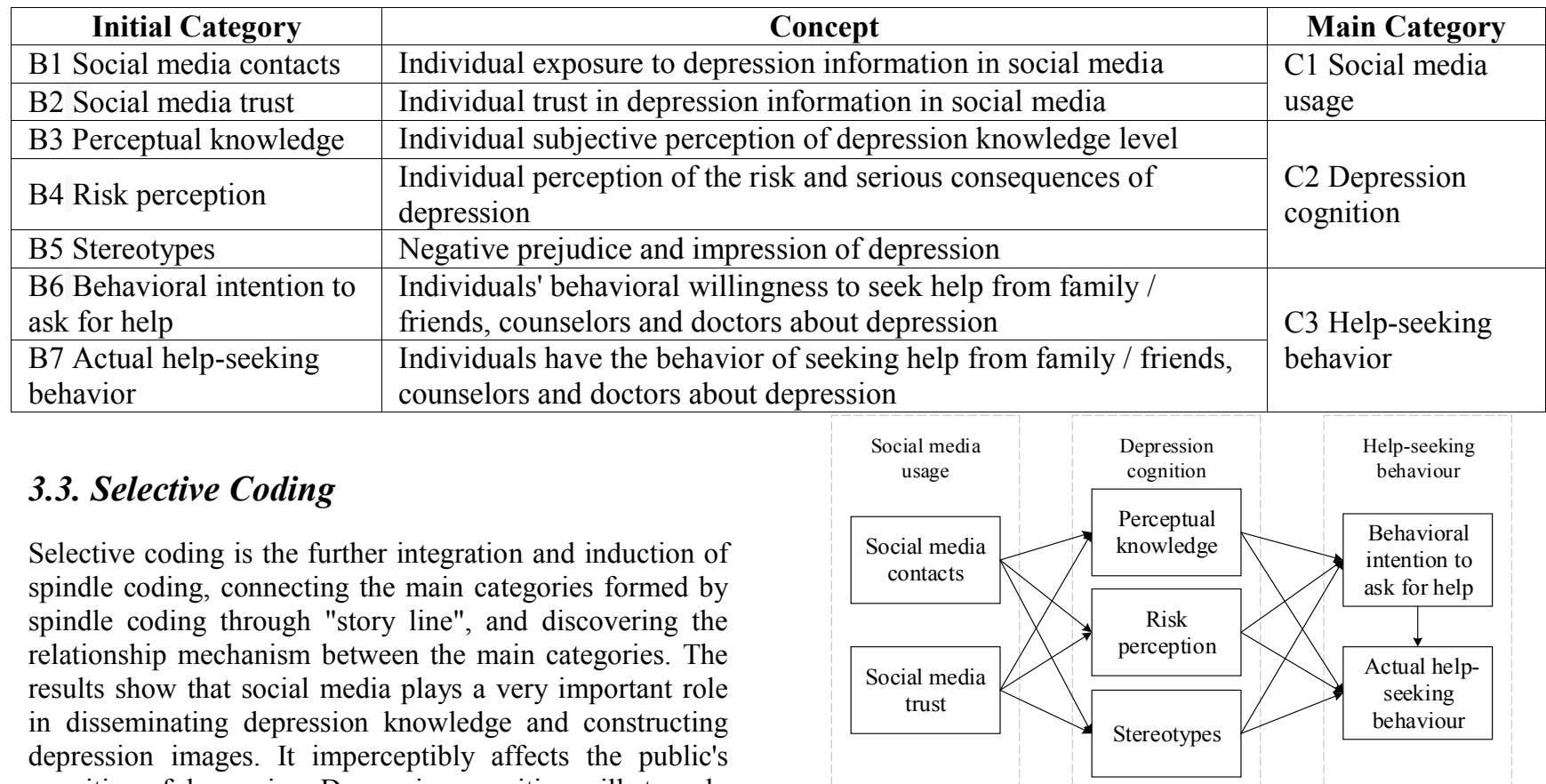
cognition of depression; Depression cognition will strongly affect their help-seeking behavior. Combined with the "environment--human--behavior" ternary interaction framework of social cognitive theory, taking the media as an important environmental factor, this paper constructs the influence framework of "media--cognition --behavior", as shown in Fig.1.

Figure 1 Model framework of the impact of social media usage on public depression cognition and helpseeking behavior

\subsection{Theoretical Saturation Test}

After the coding and model construction are completed, the remaining three interview records are used for coding again. After comparative analysis, no new concepts with a frequency of more than three times are found, and there is no logical relationship that can affect the core category. 
Therefore, it can be inferred that the theoretical model has reached saturation.

\section{RESEARCH RESULTS}

\subsection{Use of Social Media Shapes the Public's Perceived Knowledge, Risk Perception and Stereotype}

In terms of publicity and education of depression knowledge, there is a shortage of professionals, and offline educational activities are obviously limited by the level of regional economy and medical resources. Therefore, social media has become an important channel for people to obtain depression information. The process of public access to social media is also the process of information acquisition. The depression information presented in social media shapes the disease concept of depression, disseminates the research results and scientific knowledge of depression to the public, and imperceptibly affects the public's knowledge level.

At the same time, the description and presentation of depression risk in social media is an important source for the public to obtain risk information, which can amplify the risk of depression. Social media has narrowed the distance between healthy people and patients with depression. People can not only see the image of patients with depression in media reports, but also generate an intuitive understanding of depression through the first person sharing and description of patients with depression, and even generate empathy through dialogue and communication with patients with depression in online communities, Reduce stereotypes about depression.

\subsection{Perceptual Knowledge, Risk Perception and Stereotype Directly Affect Help-Seeking Behavior}

Perceptual knowledge is people's self-assessment of depression knowledge, which will guide correct behavior and provide people with solutions to problems. Risk perception is people's perception of the risk and harm of depression. People's instinct of seeking advantages, avoiding disadvantages and defense will promote people's awareness of self-protection and risk response when they perceive the risk of depression, so as to reduce the possibility of depression risk or prevent its further development. Perceived knowledge guides people "how to act", while risk perception stimulates people "should act", which together promote the public's awareness and behavior of seeking help.

Stereotypes are usually caused by the social environment. When the surrounding environment is not conducive to patients with depression, that is, when others or themselves combine patients with madness, danger, vulnerability and other images, people are often unwilling to communicate with patients with depression, and patients with depression are unwilling to reveal their illness, but choose to hide their symptoms and overcome themselves, unwilling to ask for help. Stereotype affects the public's correct understanding of depression, becomes a cognitive barrier for the public to seek help, and hinders the help-seeking behavior.

\subsection{Social Media Use Indirectly Affects Help- seeking Behavior Through Three Kinds of Cognition}

Social media does not directly affect help-seeking behavior, but mainly realizes the gradual change of helpseeking behavior through the intermediary of depression cognition. The impact of social media use on help-seeking behavior intention mainly affects the indirect effect of help-seeking behavior intention through the intermediary of perceived knowledge, risk perception and stereotype. It can be seen that social media contact mainly affects three kinds of cognition, and then indirectly affects help-seeking behavior. During the interview, one interviewee mentioned when talking about his psychological counselling that "I was very resistant to psychological counselling. Although the school has a psychological centre, I always felt it was useless. Later, I was depressed and went to microblog chat. I saw someone share the specific process of psychological counsellors helping him. I felt very scientific. Later, I also did psychological counselling". When the interviewee saw that someone in the microblog super words had done psychological counselling, he did not directly make imitation behavior, but produced a "very scientific" cognitive process, and then took corresponding actions. From the interview data, this is not an example, but a change mechanism of help-seeking behavior with a certain universal meaning.

\section{CONCLUSION}

Social media is imperceptibly affecting the public's cognition of depression, including perceived knowledge level, risk perception and stereotype. Through the cognitive level, social media has affected the public's willingness to seek help for depression to varying degrees, thus promoting the development of actual help-seeking behavior and playing a "publicity and strengthening role". Therefore, based on the social media environment, we should promote public depression cognition and helpseeking behavior from three aspects: knowledge dissemination, risk dissemination and stigma removal.

Social media should strengthen the dissemination of depression knowledge, pay attention to the three levels of knowledge dissemination effect such as the breadth, depth and scale of knowledge dissemination [9], arouse the public's attention and face up to depression, and improve the public's knowledge and ability of self-help and mutual rescue. Government agencies should strengthen the 
supervision of social media platforms, urge them to establish a risk shutdown system and improve the credibility of the media. In the process of spreading depression information on social media platforms, media institutions should skilfully apply risk communication strategies to maximize the communication effect. By opening up online interactive communication channels and encouraging patients to share their experiences, we can reduce social stereotypes and eliminate the stigma of depression.

This paper only constructs the impact model of social media use on public depression cognition and help-seeking behavior based on the grounded theory, and puts forward the countermeasures to promote public depression cognition and help-seeking behavior, but the theoretical model has not been empirically. Subsequent research will continue to put forward hypotheses and verify the hypothesis correction model through investigation and statistical analysis, so as to make its research and Countermeasures more detailed and targeted.

\section{REFERENCES}

[1] Lienemann B A, Siegel J T, and Crano W D, "Persuading People with Depression to Seek Help: Respect the Boomerang," Health Communication, vol.28, pp.718-728, 2013, DOI:

$10.1080 / 10410236.2012 .712091$

[2] H. Erin Lee, and Jaehee Cho, "Social Media Use and Well-Being in People with Physical Disabilities: Influence of SNS and Online Community Uses on Social Support, Depression, and Psychological Disposition," Health Communication, vol.34, pp.10431052, 2019, DOI:

https://doi.org/10.1080/10410236.2018.1455138

[3] Zhang Zheng, Zhao Huixin, and Chen Xuewei, "Empathy "or" Schadenfreude "-- Will Negative Information in The Circle of Friends Make Sad People More Depressed in Chinese," News and Writing, vol.1, pp.53-60, 2019, DOI: CNKI: SUN: XWXZ.0.2019-01014

[4] Natalie Berry, Fiona Lobban, Maksim Belousov, Richard Emsley, Goran Nenadic, and Sandra Bucci, "\#WhyWeTweetMH: Understanding Why People Use Twitter to Discuss Mental Health Problems," Journal of Medical Internet Research, vol.19, 2017, DOI: 10.2196/jmir.6173

[5] Moreno MA, Jelenchick LA, Egan KG, Cox E, Young H, Gannon KE, and Becker T, "Feeling Bad on Facebook: Depression Disclosures by College Students on A Social Networking Site," Depression and Anxiety, vol.28, pp.447-455,2011, DOI: 10.1002/da.20805

[6] Juliet M. Cobin, and Anselm L. Strauss, translated by Guangming Zhu, "The basis of qualitative research: the procedures and methods of forming grounded theory," Chongqing: Chongqing University Press, 2015

[7] Yanhai Liu, "Evolution Process And Influencing Factors of Social Risk Induced by Internet Rumours -Research Based on Grounded Theory in Chinese." Intelligence Journal, vol.33, pp.155-160, 2014, DOI: CNKI: Sun: qbzz.0.2014-08-026

[8] Lai Shengqiang, and Zhang Xuhui, "The Impact Mechanism of Internet Public Opinion Crisis on Internet Users' Emotional Communication -- A Grounded Theoretical Study Based on D \& G's Humiliation of China in Chinese," Modern Intelligence, vol.39, pp. 115-122, 2019, DOI: CNKI: Sun: xdqb. 0.2019-09-013

[9] Xingting Zhang, and Jianbo Lei. "Review of Public Health Knowledge Base Research in Chinese," Chinese Journal of Health Information Management, vol.14, pp. 413-417, 2017, DOI: CNKI: Sun: wsgl. 0.2017-03-011 